\title{
Analysis and Visualisation of Research Trends in Tera Hertz Meta Material: A General Review
}

\author{
Jasgurpreet Singh Chouhan ${ }^{1}$ \\ ${ }^{1}$ Department of Mechanical Engineering,Chandigarh University, Gharuan, Mohali, Punjab, 140413
}

Article History: Received: 11 January 2021; Accepted: 27 February 2021; Published online: 5 April 2021

\begin{abstract}
Terahertz Metamaterials are a type of Metamaterials, capable of interacting at terahertz (THz) frequencies. The bibliometric analysis had been conducted to understand the active authors, organizations, journals, and countries involved in the research domain of "Terahertz Metamaterials". All published articles related to "Terahertz Metamaterials" from "Scopus", were analyzed using the VOS viewer to develop analysis tables and visualization maps. This article had set the objective to consolidate the scientific literature regarding the "Terahertz Metamaterials"and also to find out the trends related to the same.The most active journals in this research domain were Optics Express and Nature Nanotechnology. The most active countries were China, Greece, and the United States of America. The leading organizations were the Ministry of Education of China and Tianjin University of China.The most active authorswere Zhang X., Zhang W., and Averitt R.D. Keywords: Metamaterial,Terahertz Metamaterials, Bibliometric analysis, VOS viewer,
\end{abstract}

\section{Introduction}

Metamaterials are engineered or composite materials with special or extra features than natural materials. Due to the special nature of Metamaterials, the potential usage of Metamaterialsis diverse including energy, aerospace, medical, infrastructure, and many more[1][2]. Terahertz Metamaterials are a type ofMetamaterials, capable of interacting at terahertz $(\mathrm{THz})$ frequencies. Terahertz frequencies are usually defined in a range 0.1$10 \mathrm{THz}$. Many materials exhibit a weak and inconsistent response to terahertz frequencies, this property is known as terahertz gaps. The problem of the terahertz gap of materials can be solved byTerahertz Metamaterials[3][4], moreover, this technology would revolutionize theexisting technology and performances in the fields of imaging, especially for security screening, skin cancer detection, all-weather navigation, bio-detection [5] and sensing[4]electrical and optical control[3].

1.1 Research Objectives

a) To consolidate the literature regarding the Terahertz Metamaterials

b) To find out the trends related to research in the Terahertz Metamaterials

The following research questions are framed for conducting bibliometric analysis systematically.

1.2 Research Questions

a) Who are the active researchers working on the Terahertz Metamaterials?

b) Which are the main organizations and countries working on Terahertz Metamaterials?

c) Which are the main journals related to Terahertz Metamaterials?

1.3 Significance of this research

Terahertz Metamaterialsis an important research niche in material engineering. This article points out the need for future research regarding Terahertz Metamaterials. This bibliometric analysis will be a useful platform for future researchers by realizing the top researchers, organizations, and countries involved in research regardingTerahertz Metamaterials. This bibliometric article is arranged in four sections. The first section is the introduction, followed by the discussion of the methodology by which the research was conducted. The third section deals with results and discussion. The fourth section deals with the conclusion.

\section{Research Methodology}

Scopus files had been used for this article. For the article selection, the Boolean used was TITLE ("Terahertz Metamaterials") on 05/01/2020. All the tables in this paper were created by using Microsoft Excel and VOS Viewer. Grammarly was used for spelling and grammar checks. Mendeley was used for article review and citation.This paper had been inspired by bibliometric analysis in its presentation style, analysis, and methodology from the works[6][7][8][9].

\section{Results and discussion}

3.1 Results

This first round of search produced an outcome of 1958 documents, infourlanguages, out of which 1892 documents were in English. The classification of document categories is shown in Figure 1. For improving the quality of the analysis, we had selected only the peer-reviewed articles and all other documents had not been considered. Thus after using filters "Article"and "English" the second round search produced an outcome of 1186 English articles (both open access and others) andhad been used to conduct bibliometric analysis and visualization using VOS Viewer. The English research articles in this domain since 2004 had been shown in Figure 2. 


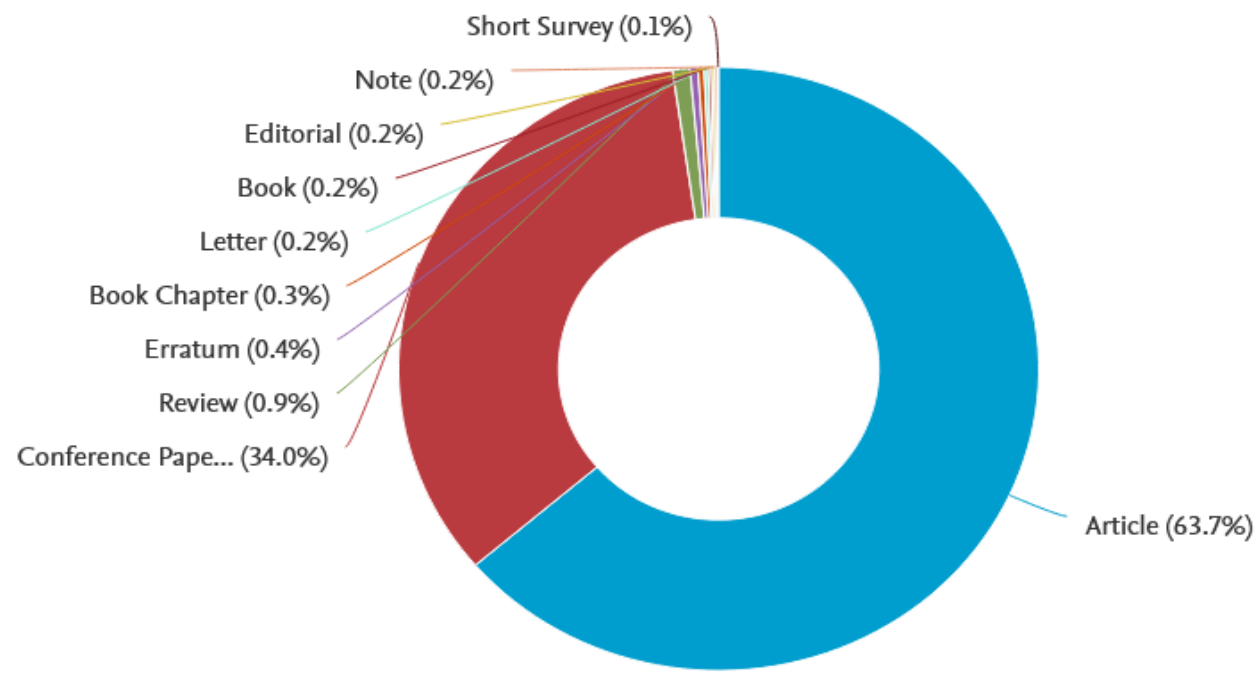

Figure 1: Classification of the documents on "Terahertz Metamaterials", Source: www.scopus.com

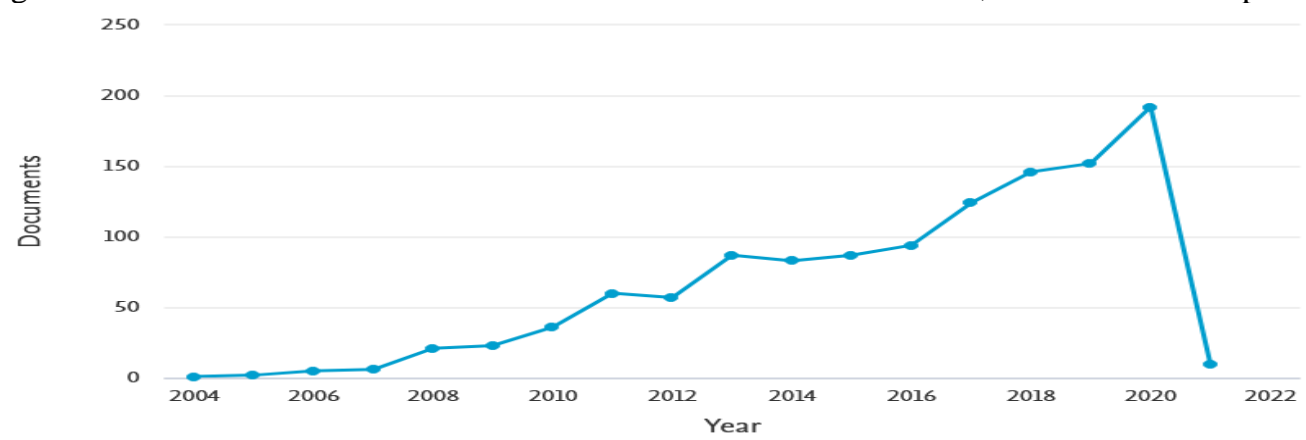

Figure 2: Period wise publication of articles, Source: WWW.scopus.com

Co-authorship analysis of top authors had been shown in figure 3. For a better presentation of the analysis, the parameters used were the minimum number of documents of an author as 20 and the minimum number of citations of authors as one. This combination plotted the map of 36 authors, in 5 clusters. The overlay visualization map of co-authorship analysis plotted in Figure 3, points out the major researchers with their strong co-authorship linkages and clusters involved.

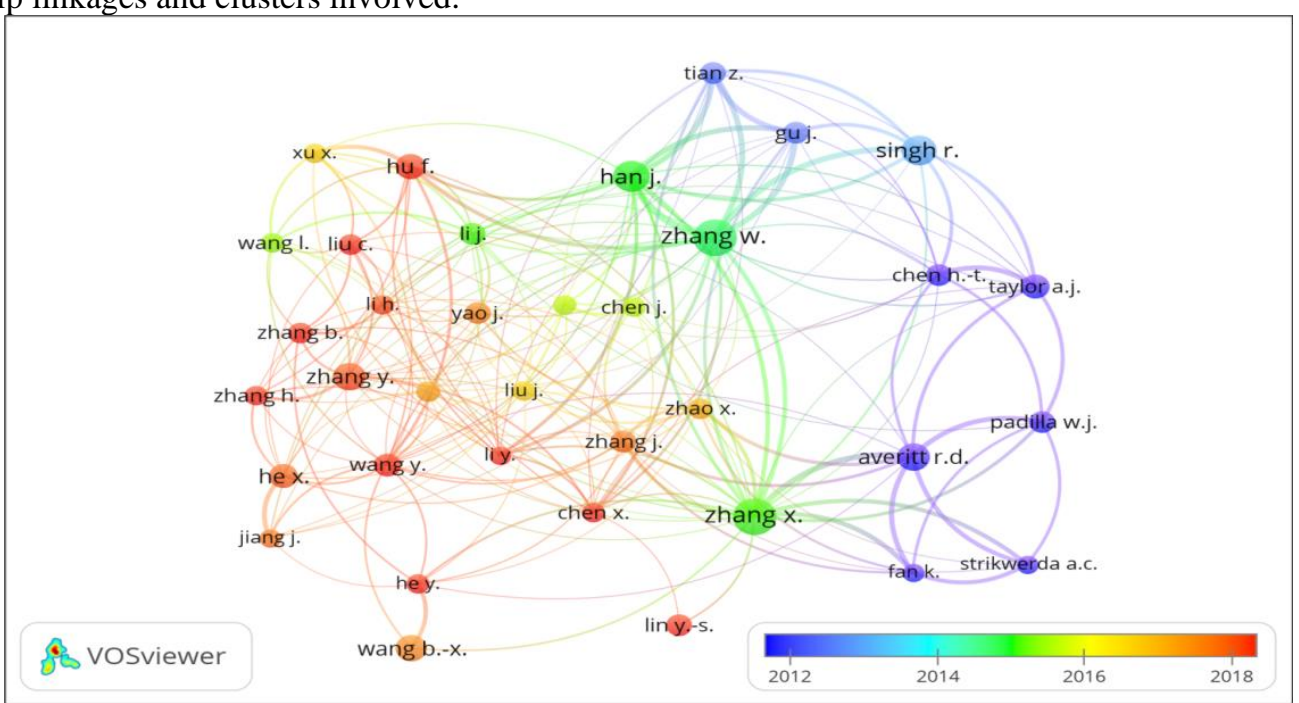

Figure 3: Co-authorship analysis on basis of authors

The citation analysis of top authors had been shown in table 1, along with co-authorship links.For the citation analysis, the parameters used werethe minimum number of documents of an author as one and the minimum citations of an author as one. 
Table 1: Highlights of most active authors

\begin{tabular}{|c|c|c|c|c|c|}
\hline Description & Authors & $\begin{array}{l}\text { Documen } \\
\text { ts }\end{array}$ & ns & \begin{tabular}{l}
\multicolumn{2}{c}{ Average } \\
citations per \\
documents
\end{tabular} & $\begin{array}{l}\text { Link } \\
\text { strength }\end{array}$ \\
\hline $\begin{array}{c}\text { Authors with the } \\
\text { highest publication }\end{array}$ & Zhang X. & 74 & 6759 & 91.34 & 453 \\
\hline $\begin{array}{l}\text { Authors with the } \\
\text { highest co-authorship } \\
\text { links }\end{array}$ & Zhang W. & 73 & 5457 & 74.75 & 481 \\
\hline $\begin{array}{l}\text { Authors with the } \\
\text { highest citation }\end{array}$ & Averitt R.D. & 42 & 9436 & 224.67 & 280 \\
\hline
\end{tabular}

In Co-occurrence analysis, we had used all keyword analyses, by keeping the minimum number of occurrences of a keyword as50. This combination plotted the map of 30thresholds, in fourclusters. The overlay visualization of co-occurrence analysis of keywords has been shown in Figure 4.

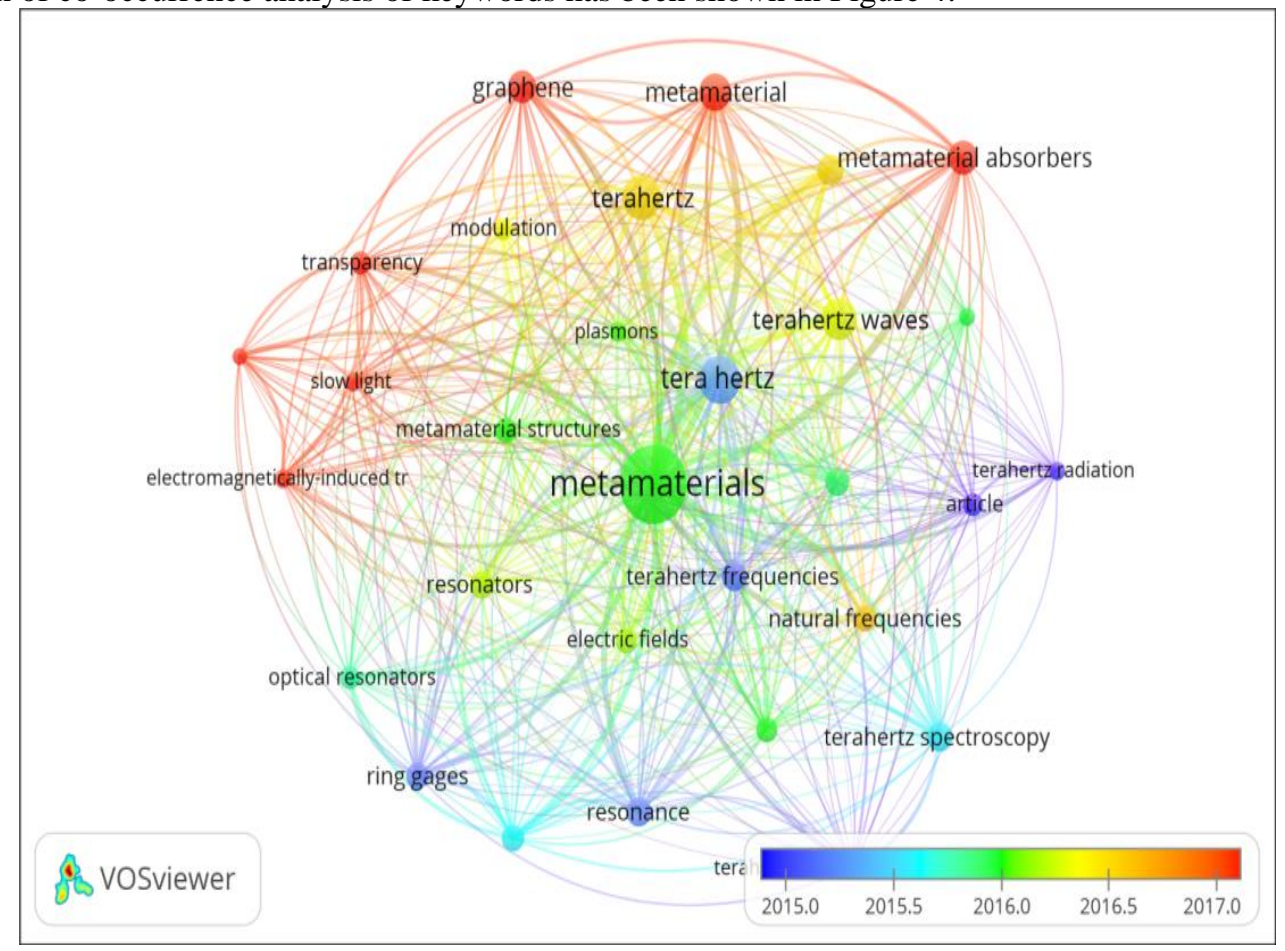

Figure 4: Co-occurrence analysis on basis of all keywords

The leadingorganizations engaged in research on "Terahertz Metamaterials" had been found out by the volume of publications and citation analysis the parameters used are the minimum number of documents of an organization as one and the minimum number of citations of organizations as one.

The leading organization in the research regarding "Terahertz Metamaterials", with the highest number of publications and citations, was the Ministry of Education China and Tianjin University (Refer to table 2).

Table 2: Highlights of the most active organization

\begin{tabular}{|l|c|c|c|c|}
\hline Organizations & Country & Document & Citatio & $\begin{array}{c}\text { Average } \\
\text { Citations } \\
\text { document }\end{array}$ \\
\hline pinistry of Education in China & China & 108 & 2849 & 26.4 \\
\hline Tianjin University & China & 97 & 3661 & 38.8 \\
\hline
\end{tabular}

Co-authorship analysis of the countries engaged in the research on "Terahertz Metamaterials" had been shown in Figure 5. For a better presentation of the analysis, the parameters used were the minimum number of documents of an author as four and the minimum number of citations of authors as one. This combination plotted the map of 30 countries, eightclusters. The overlay visualization map of co-authorship analysis plotted in Figure 5 , points out the main countries with their strong co-authorship linkages and clusters involved. 


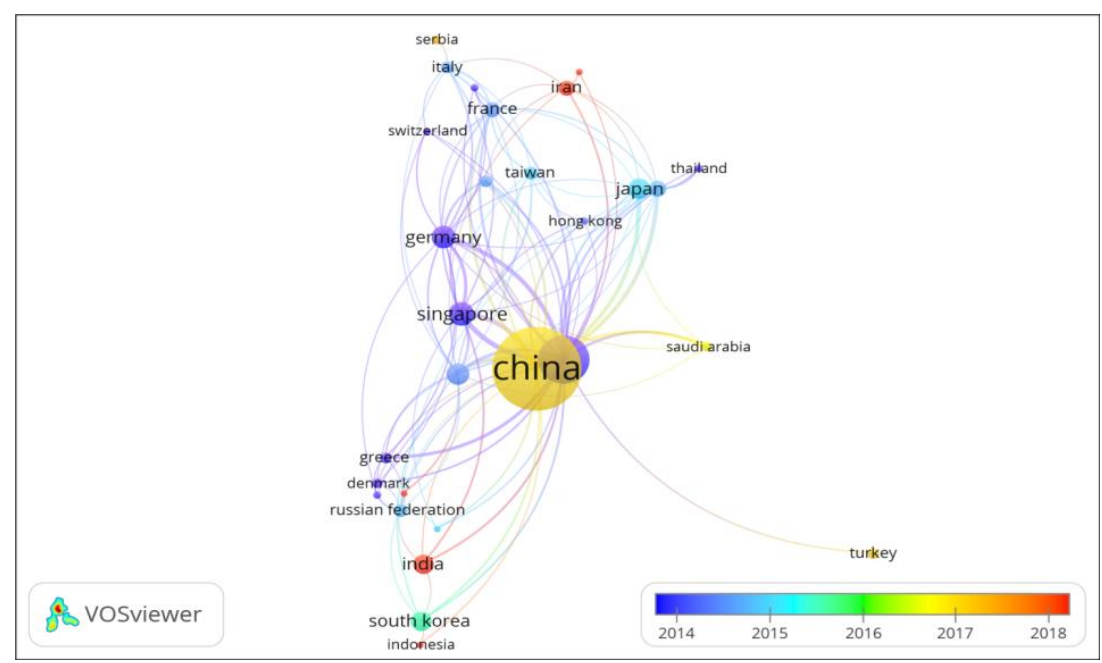

Figure 5: Co-authorship analysis on basis of countries

The citation analysis of top countries had been shown in table 3, along with co-authorship links. For the citation analysis, the parameters used were the minimum number of documents of acountry as one and the minimum citations of the country as one.

Table 3: Highlights of Active Countries

\begin{tabular}{|c|c|r|r|r|r|}
\hline Description & Country & Documen & Citatio & \multicolumn{1}{|c|}{$\begin{array}{c}\text { Average } \\
\text { citations } \\
\text { documents }\end{array}$} & $\begin{array}{c}\text { Link } \\
\text { strength }\end{array}$ \\
\hline $\begin{array}{c}\text { The country with the } \\
\text { highest publication }\end{array}$ & China & 717 & 17462 & 24.35 & 188 \\
\hline $\begin{array}{c}\text { The country with the } \\
\text { highest citations and co- } \\
\text { authorship links }\end{array}$ States of \\
$\begin{array}{c}\text { The country with the } \\
\text { Therica }\end{array}$ & Greece & 240 & 25348 & 105.62 & 202 \\
\hline
\end{tabular}

The most active countries in this research domain were China, Greece,andthe United States of America with the highest number ofpublications, average citations, and co-authorship links respectively.

Link analysis and citation analysis were used to identify the most active journal in this research domain. We have taken the parameters of the minimum number of documents of a journal as one and the minimum number of citations of a journal as one for the link analysis and citation analysis. Highlights of the most active and relevant journals related to the "Terahertz Metamaterials"are shown in table 4. Table 4shows the journal activity of this research domain through parameters of publication volume, citations, and co-authorship linkages. Optics Express and Nature Nanotechnologywere the leading journals.

Table 4: Analysis of journal activity

\begin{tabular}{|c|c|r|r|r|r|}
\hline Description & Journal details & Documen & Citatio & $\begin{array}{c}\text { Average } \\
\text { citations per } \\
\text { documents }\end{array}$ & $\begin{array}{c}\text { Link } \\
\text { strength }\end{array}$ \\
\hline $\begin{array}{c}\text { Journal with the } \\
\text { highest publications, } \\
\text { citations, and co- } \\
\text { authorship links }\end{array}$ & Optics Express & 109 & 6486 & 59.50 & 1627 \\
\hline $\begin{array}{c}\text { Journal with the } \\
\text { highest average citation }\end{array}$ & $\begin{array}{c}\text { Nature } \\
\text { Nanotechnology }\end{array}$ & 1 & 1999 & 1999 & 69 \\
\hline
\end{tabular}

From the above discussion regarding the bibliometric patterns in the research regarding the Terahertz Metamaterials,this research had observed a gradual increase in research interest regarding the Terahertz Metamaterials from the starting of the millennium and the momentum is going on positively[10].This points out the relevance and potential of this research domain (Refer to Figure 2). The most active authors in this research domainwere Zhang X., Zhang W., and Averitt R.Dwith the highest publication, co-authorship links, and citations 
respectively(Refer to table 1).The overlay analysis of top countries researching Terahertz Metamaterialsindicates that China, Greece, and the United States of Americawere the leading countries in research regarding Terahertz Metamaterialswith the highest publications, average citations,and co-authorship links(Refer to figure 5). The top journals of this research domain were identified as Optics Express and Nature Nanotechnology. Fromthese wide sources of information, researchers can focus on top journals where they can identify the most relevant and highly cited articles regarding Terahertz Metamaterials.

\section{Conclusion}

The Terahertz Metamaterialsis an interesting research domain and the most active journals related to this research domain are Optics Express and Nature Nanotechnology. The most activecountrieswere China, Greece, andthe United States of America.The leading organizations engaged in the research regarding Terahertz Metamaterialswere the Ministry of Education of China and Tianjin University of China.The most active authors who had made valuable contributions related to Terahertz Metamaterialswere Zhang X., Zhang W., and Averitt R.D. This research domain offers a new avenue for researchers and future research can be on Metamaterial, tissue engineering, optical imaging[11], [12], andoptical sensing.

\section{References}

1. M. Berger, "What are metamaterials?," Nanowerk, 2020.

2. K. M. Batoo et al., "Structural, morphological and electrical properties of $\mathrm{Cd} 2+\mathrm{doped} \mathrm{MgFe} 2-\mathrm{xO} 4$ ferrite nanoparticles," J. Alloys Compd., vol. 726, pp. 179-186, 2017.

3. R. Averitt, S. Diego, W. Padilla, H. Chen, and J. F. O. Hara, "Terahertz metamaterial devices," Proc. SPIE Int. Soc. Opt. Eng., vol. 6772 67720, 2007.

4. Xingcun Colin Tong, "Terahertz Metamaterials and Metadevices," in Functional Metamaterials and Metadevices Springer Series in Materials Science, 2018, pp. 57-70.

5. D. R. S. \& W. J. P. Claire M. Watts, David Shrekenhamer, John Montoya, Guy Lipworth, John Hunt, Timothy Sleasman, Sanjay Krishna, "Terahertz compressive imaging with metamaterial spatial light modulators," Nat. Photonics, 2014.

6. S. Arunachalam, M. K. Dhirendra Rao, and P. K. Shrivastava, "Physics research in Israel-A preliminary bibliometric analysis,” J. Inf. Sci., vol. 8, no. 5, pp. 185-195, 1984.

7. S. Ahn, J. Kang, and H. J. Lee, "Research trends in condensed matter physics based on bibliometric analysis," Information, vol. 14, no. 5, pp. 1745-1760, 2011.

8. X. Wang, Z. Xu, S.-F. Su, and W. Zhou, "A comprehensive bibliometric analysis of uncertain group decision making from 1980 to 2019,” Inf. Sci. (Ny)., vol. 547, pp. 328-353, 2021.

9. N. Niknejad, W. Ismail, M. Bahari, R. Hendradi, and A. Z. Salleh, "Mapping the research trends on blockchain technology in food and agriculture industry: A bibliometric analysis," Environ. Technol. Innov., vol. 21, 2021.

10. U. Singh, R. Salgotra, and M. Rattan, "A Novel Binary Spider Monkey Optimization Algorithm for Thinning of Concentric Circular Antenna Arrays," IETE J. Res., vol. 62, no. 6, pp. 736-744, 2016.

11. B. Goyal, A. Dogra, S. Agrawal, B. S. Sohi, and A. Sharma, "Image denoising review: From classical to state-of-the-art approaches," Inf. FUSION, vol. 55, pp. 220-244, Mar. 2020.

12. M. Kaur and V. Wasson, "ROI Based Medical Image Compression for Telemedicine Application," in Procedia Computer Science, 2015, vol. 70, pp. 579-585. 